\title{
MORE OBJECTIONS TO PATENTING ANIMALS
}

WASHINGTON, D.C.-This spring's ruling by the U.S. Patent and Trademark Office (PTO) that genetically engineered animals may be patented is stirring increased opposition on Capitol Hill. Besides the now-familiar spectre of Jeremy Rifkin, joined this time by farm organizations and animal activist groups, several members of Congress now are criticizing the PTO decision. Led by Senator Mark Hatfield ( $\mathrm{R}-\mathrm{OR}$ ), a bipartisan group from Congress seems intent on suspending the proposed patent policy for the remaining fiscal year (which runs through September) and possibly into the next.

Hatfield's amendment to cut off PTO animal patenting activities this fiscal year has already been approved by the Senate. According to Rene Tegtmeyer, the Assistant Commissioner for Patents, such a suspension would have only a "limited effect" because no animal patents are expected in this period, but he considers the move "undesirable as a precedent."

P'TO officials contend that patenting itself is a circumscribed activity that touches on matters of research, technology, and commerce-but not on health, safety, and ethics, which are the responsibility of other federal agencies. An issued patent merely gives someone the right to exclude someone else from making, using, or selling an invention, explains Tegtmeyer. The alternative to patenting is for inventors to rely on secrecy-an approach that will not stop scientists from engineering animals genetically but which may slow the pace of commercial development, he points out.

In mid-June, Representative Robert Kastenmeier ( $\mathrm{D}-\mathrm{WI}$ ), who serves on the House Committee on the Judiciary and chairs its subcommittee on courts, civil liberties, and the administration of justice, convened the first of a series of hearings on "patents and the constitution." During the meeting, Kastenmeier closely quizzed Tegtmeyer on the validity of patenting any life forms, including microorganisms (which were deemed patentable in the 1980 Diamond v. Chakrabarty Supreme Court ruling). "The Chakrabarty case opened the doors rather wide," Tegtmeyer said. Kastenmeier, however, noted that the Supreme Court's composition has changed drastically since Chakrabar- ty's narrow victory-seeming to imply that today's court might not repeat its ruling if a similar case were heard now.

Thomas Wagner, a scientist at the Edison Animal Biotechnology Center at Ohio University (Athens), who also testified at the hearing, said he favors animal patenting because it will benefit not only research universities, but also farmers-particularly those who run small operations. At the farm level, Wagner predicted that genetic engineering will lead to healthier livestock and, therefore, to a reduced need for antibiotics. For the research community, he believes the invention and patenting of genetically engineered rodents could prove useful for studying diseases such as AIDS for which only chimpanzees are now suitable models.

Predictably, John Hoyt, president of the Humane Society of the United States, disagrees. "The patenting of animals should be prohibited by Congress," he says. Adds Rifkin, "Patenting of animals reflects a human arrogance." The policy is "economically undefensible and morally repugnant." -Jeffrey L. Fox

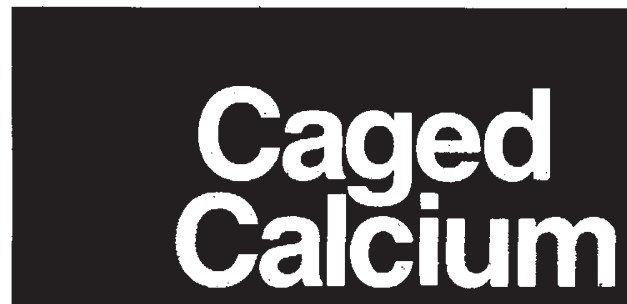

A burst of light releases $\mathrm{Ca}^{2+}$ Where you want it. When you want it.

\section{Introducing} NITR-5 and NITR-5/AM

\section{From CALBIOCHEM ${ }^{\circledast}$ Biochemicals. Committed technologically to provide the most complete line of intra- cellular probes available. Ask us. (800) 854-9256 (619) 450-9600}

\section{CALBIOCHEM ${ }^{\circledR}$ Brand Biochemicals Behring Diagnostics \\ Division of Hoechst Celanese Corp. 10933 N. Torrey Pines Rd. \\ La Jolla. CA 92037}

\section{Genetic engineering}

\section{Building blocks and Reagents for a leading technology}

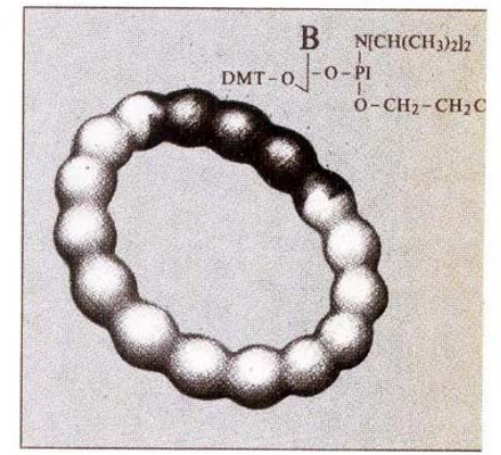

Reagent kit for Maxam-Gilbert Sequencing.

Please ask for our detailed information

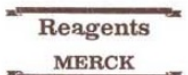

E. Merck, Frankfurter Strasse 250, D-6100 Darmstadt 1 Federal Republic of Germany 